\title{
Dedicated Perioperative Hip Fracture Comanagement Programs are Cost-effective in High-volume Centers: An Economic Analysis
}

\author{
Eric Swart MD, Eshan Vasudeva BS, Eric C. Makhni MD, MBA, \\ William Macaulay MD, Kevin J. Bozic MD, MBA
}

Received: 9 April 2015/Accepted: 30 July 2015/Published online: 11 August 2015

(C) The Association of Bone and Joint Surgeons(B) 2015

\begin{abstract}
Background Osteoporotic hip fractures are common injuries typically occurring in patients who are older and medically frail. Studies have suggested that creation of a multidisciplinary team including orthopaedic surgeons, internal medicine physicians, social workers, and specialized physical therapists, to comanage these patients can decrease complication rates, improve time to surgery, and reduce hospital length of stay; however, they have yet to achieve widespread implementation, partly owing to concerns regarding resource requirements necessary for a comanagement program.

Questions/Purposes We performed an economic analysis to determine whether implementation of a comanagement model of care for geriatric patients with osteoporotic hip fractures would be a cost-effective intervention at hospitals
\end{abstract}

All ICMJE Conflict of Interest Forms for authors and Clinical Orthopaedics and Related Research ${ }^{\mathbb{R}}$ editors and board members are on file with the publication and can be viewed on request.

Each author certifies that he or she, or a member of his or her immediate family, has no funding or commercial associations (eg, consultancies, stock ownership, equity interest, patent/licensing arrangements, etc) that might pose a conflict of interest in connection with the submitted article.

This study was performed at Columbia University, New York, NY (USA)

E. Swart, E. Vasudeva, E. C. Makhni, W. Macaulay

Department of Orthopaedic Surgery, Columbia University

Medical Center, New York, NY, USA

\section{K. J. Bozic $(\bowtie)$}

Department of Surgery and Perioperative Care, University of Texas at Austin Dell Medical School, 1912 Speedway, Suite 564, Sanchez Building, Austin, TX 78712, USA

e-mail: kevin.bozic@austin.utexas.edu with moderate volume. We also calculated what annual volume of cases would be needed for a comanagement program to "break even", and finally we evaluated whether universal or risk-stratified comanagement was more cost effective.

Methods Decision analysis techniques were used to model the effect of implementing a systems-based strategy to improve inpatient perioperative care. Costs were obtained from best-available literature and included salary to support personnel and resources to expedite time to the operating room. The major economic benefit was decreased initial hospital length of stay, which was determined via literature review and meta-analysis, and a health benefit was improvement in perioperative mortality owing to expedited preoperative evaluation based on previously conducted meta-analyses. A break-even analysis was conducted to determine the annual case volume necessary for comanagement to be either (1) cost effective (improve health-related quality of life enough to be worth additional expenses) or (2) result in cost savings (actually result in decreased total expenses). This calculation assumed the scenario in which a hospital could hire only one hospitalist (and therapist and social worker) on a full-time basis. Additionally, we evaluated the scenario where the necessary staff was already employed at the hospital and could be dedicated to a comanagement service on a part-time basis, and explored the effect of triaging only patients considered high risk to a comanagement service versus comanaging all geriatric patients. Finally, probabilistic sensitivity analysis was conducted on all critical variables, with broad ranges used for values around which there was higher uncertainty.

Results For the base case, universal comanagement was more cost effective than traditional care and risk-stratified comanagement (incremental cost effectiveness ratios of 
USD 41,100 per quality-adjusted life-year and USD 81,900 per quality-adjusted life-year, respectively). Comanagement was more cost effective than traditional management as long as the case volume was more than 54 patients annually (range, 41-68 patients based on sensitivity analysis) and resulted in cost savings when there were more than 318 patients annually (range, 238-397 patients). In a scenario where staff could be partially dedicated to a comanagement service, universal comanagement was more cost effective than risk-stratified comanagement (incremental cost effectiveness of USD 2300 per quality-adjusted life-year), and both comanagement programs had lower costs and better outcomes compared with traditional management. Sensitivity analysis was conducted and showed that the level of uncertainty in key variables was not high enough to change the core conclusions of the model.

Conclusions Implementation of a systems-based comanagement strategy using a dedicated team to improve perioperative medical care and expedite preoperative evaluation is cost effective in hospitals with moderate volume and can result in cost savings at higher-volume centers. The optimum patient population for a comanagement strategy is still being defined.

Level of Evidence Level 1, Economic and Decision Analysis.

\section{Introduction}

There are more than 300,000 hip fractures annually in the United States population, with total treatment costs estimated at more than USD 12 billion [9, 10]. In addition to the technical surgical challenges attributable to osteoporotic bone, many patients with these fragility fractures are elderly, with multiple comorbidities, and can be difficult to manage perioperatively from a medical perspective $[3,18,20]$.

Because of the complex medical demands of these patients, some centers have evaluated the use of a dedicated multidisciplinary service where patients with hip fractures are comanaged by an orthopaedic surgeon along with a dedicated internal medicine physician (often referred to as a hospitalist) [22, 24, 39, 52] during their acute hospitalizations. This model of care also is called "multidisciplinary care" or "comprehensive geriatric care". There have been multiple comanagement strategies reported [26], which range from adding one hospitalist to an existing service to comanage with the orthopaedist [16], to devoting an entire section of a hospital to specifically focus on hip fracture care, with staff exclusively dedicated to that task [60]. The team also may include a group of dedicated staff including specially trained therapists and social workers. Of the more successful models, two of the common features are (1) a shift in focus where both physicians act as a patient's primary caregiver as opposed to the traditional model of admission to a single service with the other service acting as a consultant, and (2) a shared goal that common medical and surgical complications should be anticipated rather than treated after their occurrence. This approach has decreased complication rates $[5,17,22,45,64]$, time from injury until the operating room [4, 24, 52], hospital length of stay [5, 17, 24, 28, $39,40,52,70]$, and has improved osteoporosis treatment $[22,28]$.

However, restructuring the care system and recruiting additional medical personnel would require additional dedicated resources, with associated increased costs. Highquality economic studies have evaluated the benefits of directing resources toward the focused goal of reducing time to the operating room [19] and the benefits of early initiation of osteoporosis treatment [31, 32, 35]. Additionally, numerous studies have identified important predictors of perioperative complications, costs, and mortality $[5,13,18,41,46,49,53,54,65]$, suggesting that different patient populations may have different predisposing risk factors, and thus experience different degrees of benefit from a comanagement system. Although the financial issues associated with comanagement programs have been explored [14, 19, 37], to our knowledge no formal economic analysis based on decision analysis principles-which can be used to synthesize results over multiple studies and create generalizable conclusions-has been performed.

The primary objective of this study was to evaluate whether implementation of a comanagement model of care for geriatric patients with osteoporotic hip fractures would be a cost-effective intervention. We sought to determine the volume of cases needed and cost parameters in which comanagement would "break even" (result in cost savings) or at least be a cost-effective expense. Finally, we evaluated whether a preoperative risk stratification strategy may help identify patients likely to maximize benefit from the additional resources necessary for more intensive comanagement.

\section{Materials and Methods}

\section{Study Design}

This was an economic decision analysis study conducted according to the published guidelines [27]. A model was created evaluating the treatment of geriatric patients (an average age of 80 years was used for the base case [23, 30, $36,56]$ ) with osteoporotic hip fractures using (1) admission to a traditional single service, (2) universal admission to a 
formally comanaged service with a specifically dedicated geriatric healthcare team (with resources in place to expedite time to the operating room), or (3) a risk-stratified model where patients who were high risk and sicker are assigned to a comanagement service, and patients who are healthier, with less-complex conditions were admitted to a lower-cost traditional service. Costs and clinical outcome probabilities were based on reported values $[3,4,12,17$, $19,23,37,43,48]$. We used a societal basis for cost calculations, assuming an incremental cost-effectiveness ratio (ICER) threshold of USD 100,000 per quality-adjusted lifeyear (QALY) as a cutoff for cost-effective treatment [8]. The decision tree model was created and analyzed using decision analysis software (TreeAge Pro; TreeAge Software Inc, Williamstown, MA, USA). The broadest (societal) perspective was used for calculations.

Throughout our analysis, we determined operating parameters for a comanagement service to be either (1) cost effective: improved health outcomes but with increased costs (with cost increase less than our defined ICER cutoff of USD 100,000 per QALY), or (2) cost saving: improved health outcomes but decreased costs (dominant strategy).

Our primary goal was to evaluate the cost effectiveness of a comanagement service under moderate hip fracture volumes, and conduct a break-even analysis to evaluate the minimum case volume required for a comanagement program to be either cost effective or cost saving. This calculation assumed the scenario in which a hospital could hire only one hospitalist (and therapist and social worker) on a full-time basis, with overtime fees paid to expedite preoperative evaluation paid on a per case basis. Additionally, we evaluated a scenario where full-time staff already was present at the hospital and could be partially dedicated to a comanagement service based on case volume, with funding required just to offset that partial time commitment.

\section{Time to Operating Room and Mortality}

Dy et al. [19] analyzed the value of various strategies to reduce time to the operating room for patients with hip fractures, including the addition of a hospitalist and technologist to expedite preoperative workup and clearance. Since this approach was cost effective, we assumed that a structured comanagement program also would include a streamlined workup process [19]. Based on their analysis, we estimated that $30 \%$ of the patients would have a delay more than 48 hours in a traditional system, compared with $10 \%$ in a comanaged system with an expedited preoperative workup strategy (risk ratio of operative delay of 0.33 ) [19, 57] (Table 1).

In terms of postoperative mortality, we assumed a baseline 1-year mortality rate of $20 \%$ [12, 23, 30, 36, 56,
57], with a $30 \%$ increase in mortality for patients with operative treatment delayed more than 48 hours, based on several meta-analyses [48, 57, 59]. The 95\% CI of mortality increase was based on the broadest ranges given in these meta-analyses, and ranged from a $5 \%$ to a $49 \%$ increase. Life expectancy after the first year of surgery was assumed to be 8 years based on US actuarial tables [1, 36]. Other than a direct mortality benefit from an earlier time to the operating room, we assumed the comanagement system had no other effects in overall mortality rate [24, 28, 61] (Table 1).

\section{Costs}

Several models of comanagement exist for geriatric patients with hip fractures, all with different levels of resource utilization. For our model we used a commonly reported model, and assumed that the care team would include an orthopaedic surgeon and a dedicated hospitalist, along with therapists and social workers specifically designated to a comanagement team [25, 38, 70]. Surgeon fees and operating room time and costs were not included in the analysis as it was assumed that both patients received the same surgical care regardless of perioperative medical management strategy.

For analysis, we evaluated the case volume necessary to justify hiring an entire dedicated team, assuming a full annual salary for each team member. Salaries were taken based on reported values [43, 66, 68], which then were calibrated to contemporary (2015) US dollars based on the consumer price index [69]. To account for the cost of a typical benefits package, the total cost for each staff was increased $25 \%$ above their base salary. For our base-case calculation, we used the approximate median volume in major US metropolitan areas of 100 cases per year [14]. Additionally, we calculated costs on a per-case basis assuming each team member was working at their maximum capacity for use in the scenario where staff could be dedicated on a part-time basis based on volume and in the sensitivity analysis. To calculate service capacity, we chose to use a length of stay of 10 days based on the average values given in the studies used as inputs in this analysis. Additionally, although patients with hip fractures are almost always "cleared" by an internal medicine physician before operative fixation, we assumed that the major requirement of time and resources of the hospitalist staff was in postoperative care, and that their initial clearance workup did not have any significant associated costs.

Physician salaries are difficult to estimate using traditional literature review, as physician reimbursement is not commonly reported in academic literature. Instead, we used various online sources. The terms "Hospitalist AND 
Table 1. Input values used to calculate cost effectiveness of comanagement program

\begin{tabular}{|c|c|c|c|}
\hline Description & Value & Range tested & References \\
\hline \multicolumn{4}{|l|}{ Cost } \\
\hline Additional length of stay in hospital (USD/day) & 699 & $400-800$ & {$[64,69]$} \\
\hline Annual case volume for base case (cases/year) & 125 & $54-318$ & {$[14]$} \\
\hline \multicolumn{4}{|l|}{ Cost of a comanagement service } \\
\hline Hospitalist annual salary (USD) ${ }^{+}$ & 268,000 & & {$[43,66,69]$} \\
\hline Dedicated physical therapist annual salary (USD) ${ }^{+}$ & 105,200 & & {$[68,69]$} \\
\hline Dedicated social worker annual salary (USD) ${ }^{+}$ & 67,200 & & {$[68,69]$} \\
\hline Diagnostic technologist to expedite preoperative workup (USD/case) & 58 & & {$[19,50,68,69]$} \\
\hline Cost per case assuming maximum service capacity (USD/case) & 1406 & $930-1870$ & \\
\hline \multicolumn{4}{|l|}{ Risk reduction with comanagement } \\
\hline Average length of stay (days) & 10.6 & $6-13$ & {$[5,17,24,28,39,40,45,52]$} \\
\hline Decrease in length of stay with comanagement (days) & 2.28 & $2.00-2.56$ & {$[5,17,24,28,39,40,45,52]$} \\
\hline Baseline percentage of patients with operative delay $>48$ hours $(\%)$ & 30 & $5-49$ & {$[19,57]$} \\
\hline $\begin{array}{l}\text { Reduction in } 48 \text {-hour operating room delay with expedited } \\
\text { comanagement system (risk ratio) }\end{array}$ & 0.33 & $0.1-0.6$ & {$[19,48,57,59]$} \\
\hline \multicolumn{4}{|l|}{ Preoperative risk stratification } \\
\hline Prevalance of high-risk* patients in study population $(\%)$ & 74.0 & $45-92$ & {$[18,53,54,71]$} \\
\hline Perioperative mortality increase in high-risk patients (odds ratio) & 3.6 & $2.6-4.8$ & {$[18,53,54,71]$} \\
\hline Average length of stay increase in high-risk patients (\%) & 28.0 & $10-40$ & {$[13,18,49]$} \\
\hline \multicolumn{4}{|l|}{ Probability of death } \\
\hline Age at the time of fracture & 80.0 & None & {$[23,30,36,56]$} \\
\hline Baseline 1-year mortality if operative delay $<48$ hours ( $\%$ ) & 20.0 & $15.0-30.0$ & {$[12,23,30,36,56,57]$} \\
\hline Increase in mortality if operative delay $>48$ hours (risk ratio) & 1.3 & $1.05-1.49$ & {$[48,57,59]$} \\
\hline Average life expectancy $1+$ year after fracture (years) & 8.0 & $5-10$ & {$[1,36]$} \\
\hline \multicolumn{4}{|l|}{ Quality of life/utility } \\
\hline Utility after surgical repair of hip fracture & 0.7 & $0.63-0.8$ & {$[6,7,21,46,62,67]$} \\
\hline
\end{tabular}

* Defined as American Society of Anesthesiology score of 3 or 4, or Nottingham Hip Fracture Score of 4 or greater; ${ }^{+}$includes an additional $25 \%$ increase to account for benefits.

Salary" were searched though Google (www.google.com), and sites were screened to identify those reporting the results of internal, independent surveys. These results were combined with the salary of an internal medicine physician reported by the US Bureau of Labor Statistics [68] and the mean result was used, resulting in an average salary of USD 214,400 for the base case, or USD 268,000 after benefits (Table 2). For calculations of costs on a per-case basis, we assumed that a hospitalist working in conjunction with an already-established orthopaedic surgery service infrastructure could safely cover a census of at least 10 patients at a time, based on studies of independent hospitalists managing a census of seven to 12 patients [15, 29, 44]. With an average length of stay of 10 days, one hospitalist would be able to handle an annual volume of approximately 350 patients. Along with the regular salary, we assumed an increase of $20 \%$ over the standard salary to cover the work done during calls for off-hours emergency evaluation to expedite time to the operating room. These calculations resulted in a per-case cost of a hospitalist of USD 899.
Table 2. Reported hospitalist salaries

\begin{tabular}{lll}
\hline Study or Organization & $\begin{array}{l}\text { Salary } \\
\text { (USD) }\end{array}$ & Reference \\
\hline Li (SHM Society of Hospital Medicine) & 210,338 & {$[43]$} \\
Today's Hospitalist & 231,035 & {$[66]$} \\
Kane \& Peckham (Medscape) & 188,000 & {$[34]$} \\
Salary.com & 207,851 & {$[55]$} \\
SHM Society of Hospital Medicine & 252,996 & {$[58]$} \\
Payscale.com & 194,019 & {$[51]$} \\
Medical Group Management Association & 240,352 & {$[47]$} \\
$\quad$ MGMA) & & \\
US Bureau of Labor and Statistics & 190,530 & {$[68]$} \\
$\quad$ internist salary) & & \\
Average & 214,390 & \\
\hline
\end{tabular}

Physical therapist and social worker salaries were based on national averages from the US Bureau of Labor Statistics [68], which were USD 84,200 and USD 53,800 respectively (USD 105,200 and USD 67,200 after benefits). 
We estimated that a busy therapist could see at least eight patients daily, whereas one social worker could manage approximately 18 patients, which was based on internal institutional experience. Along with our assumed length of stay of 10 days, this led to a service capacity of 286 cases annually and a per-case cost of USD 367 for the physical therapist. The social worker has a service capacity of 644 cases per year and a per-case cost of USD 82.

Finally, we assumed that an expedited workup for afterhours cases would be required in $46 \%$ of cases [50], and would require a dedicated technologist with 3 hours of overtime $(150 \%)$ wages at a mean wage of USD 28 per hour [19, 68, 69], adding an additional cost of USD 58 per case. The total per case costs of all staff were combined for a total average cost per case of USD 1406. An error estimate of $33 \%$ greater or less than that cost was used in the sensitivity analysis (Table 1).

\section{Complication Rates and Length of Stay}

Multiple studies have evaluated how a dedicated comanagement service has affected specific postoperative complication rates (Table 3) and reduced length of stay. In the current analysis, we assumed that the major financial benefits of the addition of a comanagement service were manifest through decreased length of stay. To better quantify these effects, we conducted a systematic literature review using PubMed, searching the terms "hip fracture comanagement" and "hip fracture multidisciplinary care". We included studies that evaluated the outcomes of a true comanagement system, where patients were actively managed by an orthopaedic team and a medical team (hospitalist or geriatrician), as opposed to one service simply being consulted. To be included, the study also had to have a clear comparator group, usually historical controls in the same institution or direct comparison to a randomized cohort. The weighted mean difference of

Table 3. Reductions in complication rates with comanagement

\begin{tabular}{llll}
\hline Complication & $\begin{array}{l}\text { Incidence } \\
(\%)\end{array}$ & $\begin{array}{l}\text { Relative } \\
\text { risk }\end{array}$ & References \\
\hline Delirium & $5.9-32$ & $0.5-0.64$ & {$[22,46,70]$} \\
Sepsis & 6.7 & 0.54 & {$[22]$} \\
Venous thromboembolism & 1.3 & 0.28 & {$[22]$} \\
$\begin{array}{l}\text { Pneumonia } \\
\text { Intensive care unit }\end{array}$ & 0.5 & 0.13 & {$[22]$} \\
$\quad$ admission rate & 23 & 0.48 & {$[17]$} \\
$\begin{array}{l}\text { Readmission } \\
\text { Venous thromboembolism }\end{array}$ & 94 & $0.27-0.97$ & {$[22,61]$} \\
$\quad$ prophylaxis & & 1.49 & {$[22]$} \\
$\begin{array}{l}\text { Osteoporosis treatment } \\
\text { P }\end{array}$ & 69 & 5.75 & {$[22,39]$} \\
\hline
\end{tabular}

length of stay and 95\% CI was calculated using Review Manager 5.0 (http://tech.cochrane.org/revman/download), with length of stay treated as a continuous variable.

The initial PubMed review returned 235 studies, of which 220 were excluded by title and abstract search, and an additional seven were excluded after review of full text, leaving eight studies for inclusion. One study was a level 1 prospective randomized control trial [70], and the remaining seven were level 3 studies with historical controls [5, 17, 24, 28, 39, 40, 52]. Results of our metaanalysis showed an average reduction in length of stay by 2.28 days (95\% CI, 2.00-2.56 days) (Fig. 1). The cost of a day in the hospital was based on reported values [64] and scaled by the consumer price index [69] to USD 699.

\section{Risk Stratification}

Different tools to estimate perioperative risk of elderly patients with hip fractures [11] have been described. For our model, we conducted a literature review using PubMed searching the terms "hip fracture mortality risk prediction", and identified studies which specifically described two critical factors: (1) odds ratio (OR) of mortality as a function of risk stratification, and (2) change in length of stay as a function of risk stratification. We defined "high risk" as an American Society of Anesthesiologists (ASA) score of 3 or 4 and Nottingham Hip Fracture Score of 4 or greater.

Of the 65 studies returned by our search, we identified four that calculated the OR for perioperative mortality [18, $53,54,71]$ as a function of risk status. The individual ORs reported were 4.78 [54], 4.21 [18], 2.81 [71], and 2.58 [53], and were combined to generate a mean OR of 3.6, which was used for the base case in the model, although the extreme ranges (2.58 and 4.78) were included in the sensitivity analysis. In those studies, the prevalences of highrisk patients were 92\% [53], 86\% [54], 73\% [18], and 45\% [71], and an average value of $74 \%$ was used, with the range of $45 \%$ to $92 \%$ used in the sensitivity analysis.

Similarly, we identified three studies that found a correlation between length of stay and preoperative risk assessment [13, 18, 49]. The three studies reported increased length of stay in higher-risk patients of 40\% [49], 35\% [13], and $10 \%$ [18], and an average increased length of stay of $28 \%$ for high-risk patients was used for the base case, with a range of $10 \%$ to $40 \%$ used in the sensitivity analysis.

Sensitivity Analysis

Sensitivity analyses were performed on all the variables (Table 1) to evaluate their effect on the model's results. 


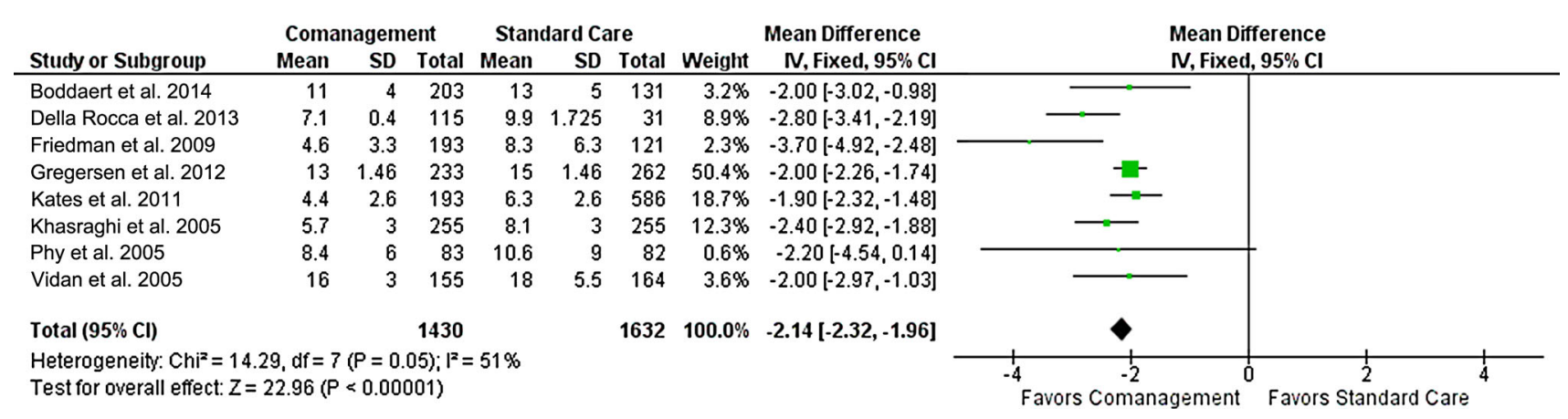

Fig. 1 A forest plot and meta-analysis of the literature shows the reduction in length of stay after implementation of a comanagement protocol, with an average reduction in length of stay of 2.28 days (95\% CI, 1.96-2.32). IV = interval value.

We evaluated three different scenarios for the effect of volume on cost effectiveness: (1) that of a high-volume center (determined by the cost-saving component of the break-even analysis), (2) a middle-volume center, based on the median annual hip fracture volume seen in US metropolitan areas [14], and (3) a lower-volume center (determined by the cost-effective component of the breakeven analysis). In that analysis, a given annual case volume was set, and all other parameters were allowed to randomly vary within 95\% CIs, and a Monte Carlo simulation was used to determine the odds of a given strategy being preferred over a range of incremental cost-effectiveness ratios (generating a result known as an "acceptability curve").

Additionally, to determine the preferred strategy between universal and risk-stratified comanagement, a multiway sensitivity analysis was performed to evaluate the combined effects of cost of comanagement, prevalence of patients at high-risk in the fragility hip fracture population, increased mortality in high-risk patients, and increased costs (length of stay) in patients considered high risk.

\section{Results}

Base case and break-even analysis

For the base case universal comanagement was the most cost-effective strategy. Using an annual volume of 100 patients), a traditional service had a total cost of USD 7409 and a QALY gain of 4.38, risk-stratified comanagement had a cost of USD 9467 and a QALY gain of 4.44, and universal comanagement had a cost of USD 10,286 per case and a QALY gain of 4.45. We found improved outcomes at a cost of USD 41,000 per QALY compared with traditional comanagement, and USD 81,900 per QALY compared with risk-stratified comanagement. Varying volume, a hospital adopting comanagement would need to see a total annual volume of 54 fractures per year to be cost effective and 318 fractures per year to result in cost savings (Fig. 2).

In the scenario with part-time staff and salary accounted for proportionately to the number of hip fractures, universal and risk-stratified comanagement provided lower costs and better health outcomes than traditional management. A traditional service had a total cost of USD 7409 and a QALY gain of 4.38, risk-stratified comanagement had a cost of USD 7199 and a QALY gain of 4.44, and universal comanagement had a cost of USD 7222 per case and a QALY gain of 4.45. Universal comanagement was more cost effective with an incremental cost effectiveness ratio of USD 2300 per QALY.

\section{Sensitivity Analyses}

Probabilistic sensitivity analysis was conducted at three different case volumes: 54 cases per year at a low-volume center, 100 per year at a middle-volume center, and 318 per year at a high-volume center (Fig. 3). A high-volume center was cost effective for all scenarios. A middle-volume center was more likely to be cost effective for most scenarios when the willingness to pay (ICER threshold) was greater than USD 40,000 per QALY. The low-volume center was more likely to be cost effective when the ICER threshold was at or greater than USD 100,000 per QALY.

Evaluating the overall cost of a comanagement program in a one-way sensitivity analysis, once the cost increased to USD 1282 per case, a risk-stratified strategy became less expensive, and once the cost increased to more than USD 1627, traditional management became less expensive. However, although slightly more expensive, a risk-stratified comanaged strategy was still cost effective (less than USD 100,000 per QALY) until the cost of comanagement increased to more than USD 10,000 per case (Fig. 4).

Length of stay benefit of a comanagement program showed a similar trend. Comanagement was less expensive 


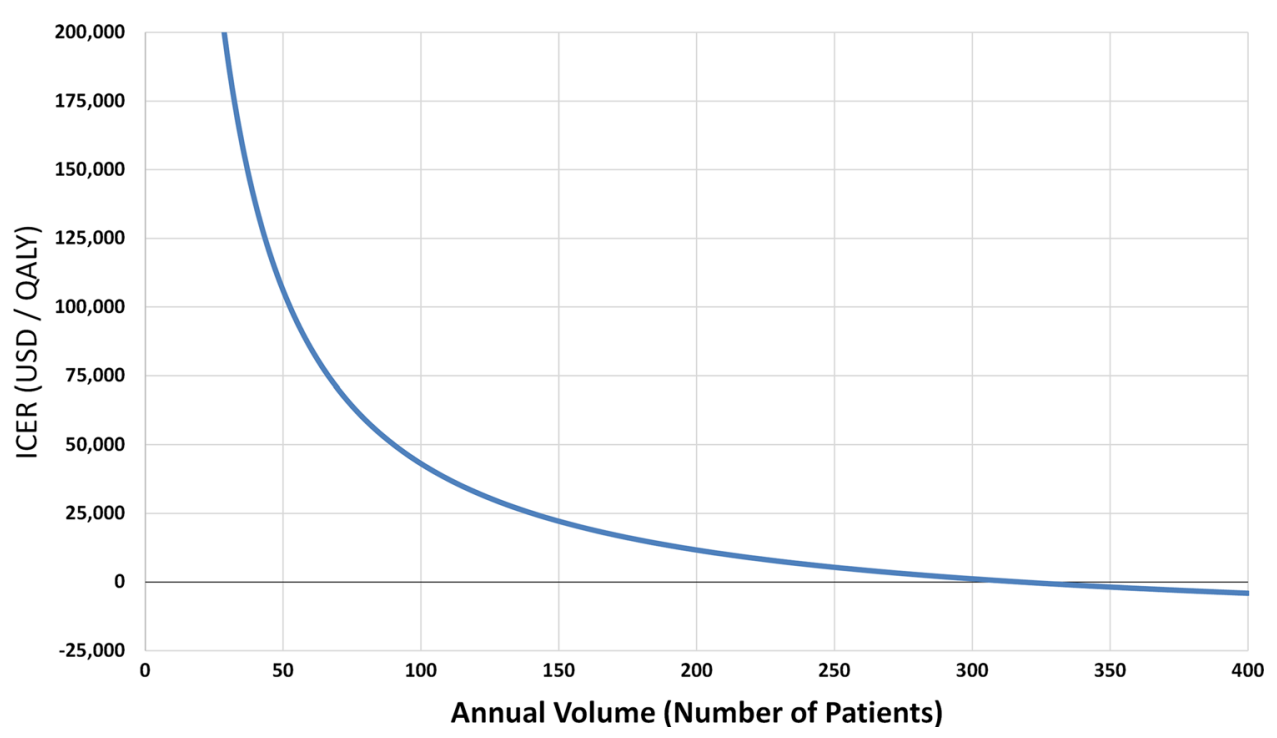

Fig. 2 The incremental cost-effectiveness ratio (ICER) is shown as a function of total annual patient volume. At more than 54 patients annually, the program becomes cost effective (ie, the ICER decreases below the threshold of USD 100,000 per QALY). For more than 318 cases annually, it becomes cost saving. QALY = quality-adjusted lifeyears.

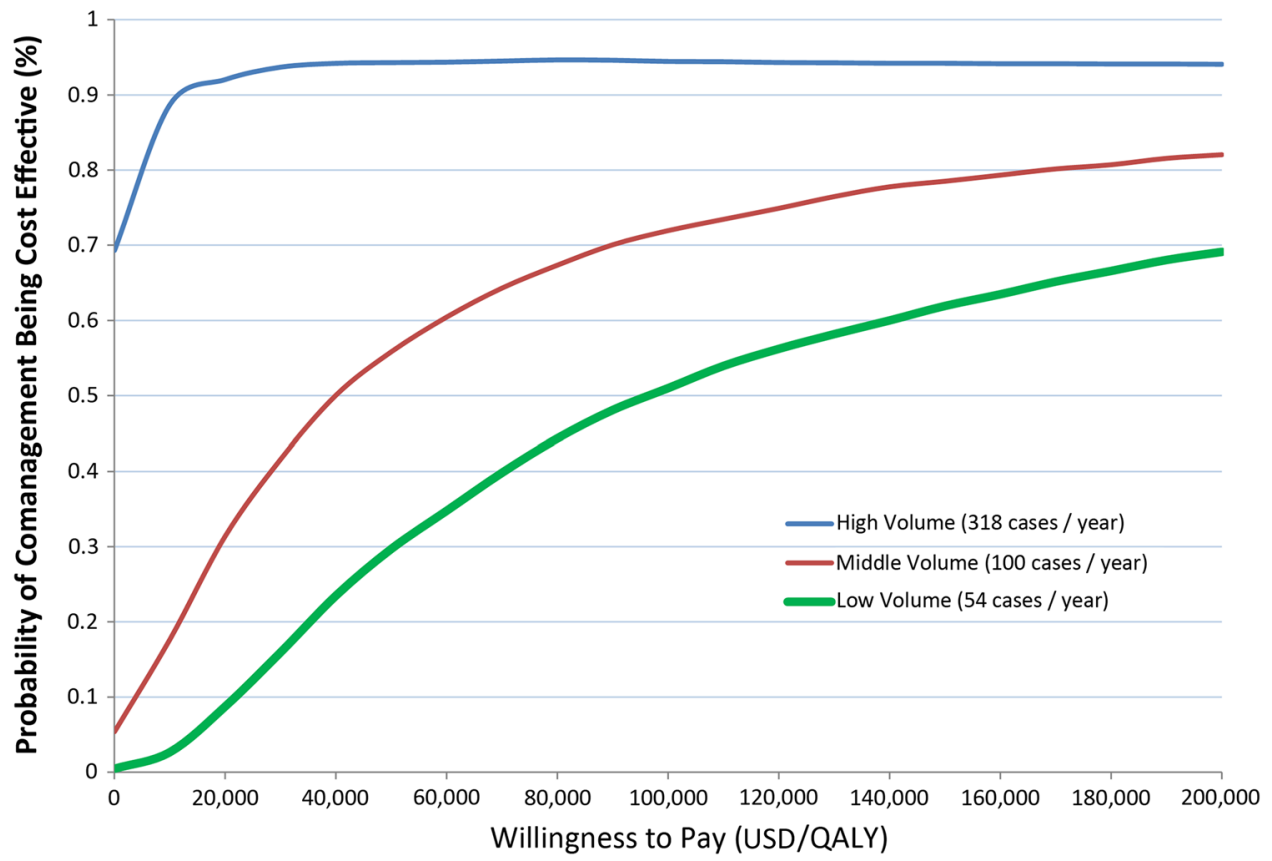

Fig. 3 Acceptability curve results of probabilistic sensitivity analysis show that at high volume centers, comanagement is the preferred option for all levels of willingness to pay. For middle-volume centers, comanagement is more likely preferred when the willingness to pay is

than traditional management provided the length of stay benefit was 1.8 days or greater. For all length of stay benefits, universal comanagement was the most cost-effective strategy (Fig. 5).

For all values of costs, mortality increase, length of stay increase, and prevalence of high-risk patients, universal comanagement was the most cost-effective option. greater than USD 40,000 per QALY, whereas for low-volume centers, comanagement is preferred only when willingness to pay is greater than USD 100,000 per QALY. QALY = quality-adjusted life-years.

\section{Discussion}

Hip fractures in geriatric patients are common injuries that are managed routinely by orthopaedic surgeons, and the number of these injuries are likely to increase with an aging population. Therefore, critical analysis of the costs of care is necessary in optimizing utilization of available medical 


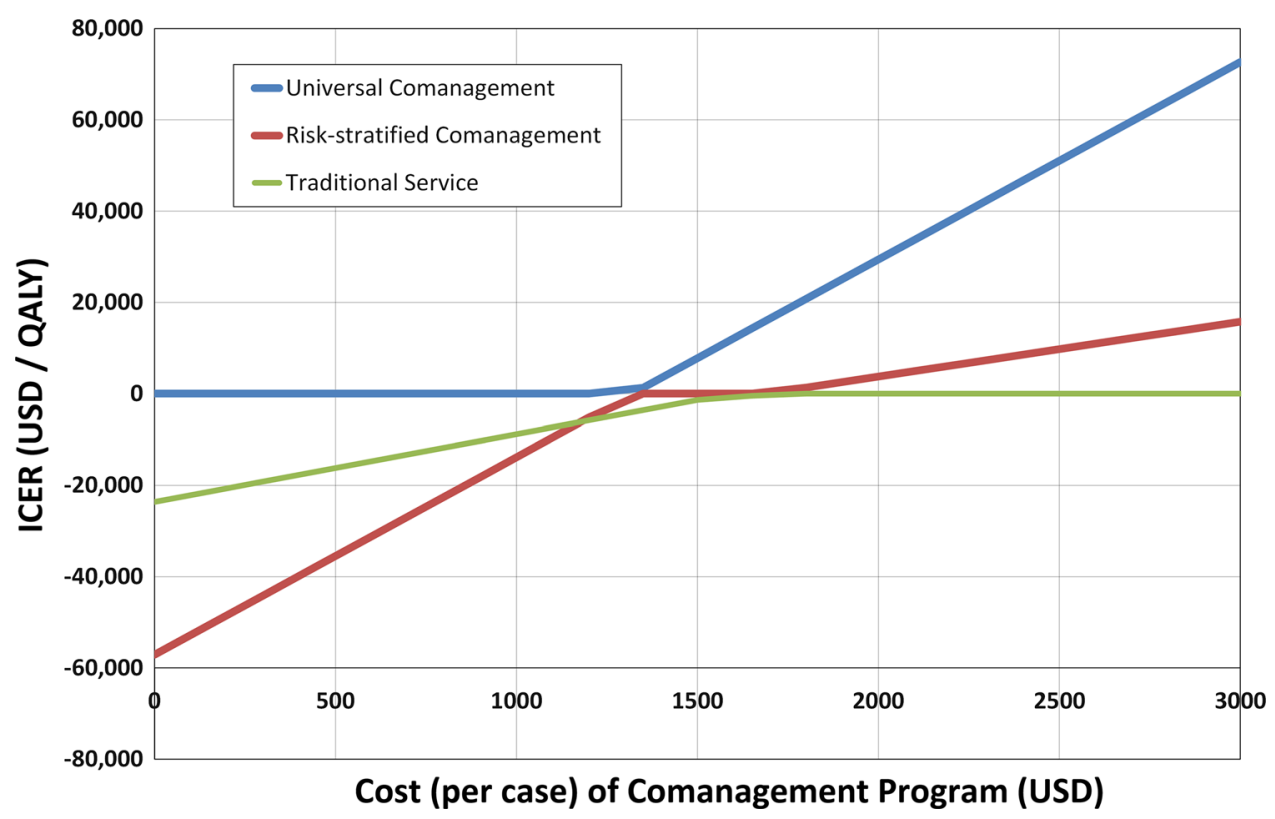

Fig. 4 The estimated cost (per case) to implement a comanagement program and its effect on incremental cost-effectiveness ratio (ICER) are shown. For low-cost programs (less than USD 1200 per case), universal comanagement is less expensive and more effective (dominant, ICER is negative). Universal comanagement remains cost effective (less than USD 100,000 per QALY) at more than USD 1200 until the cost increases to greater than USD 3600 per case, at which point a risk-stratified comanagement system is cost-effective as long as the cost of comanagement is less than USD 10,000 per case. QALY = quality-adjusted life-years.

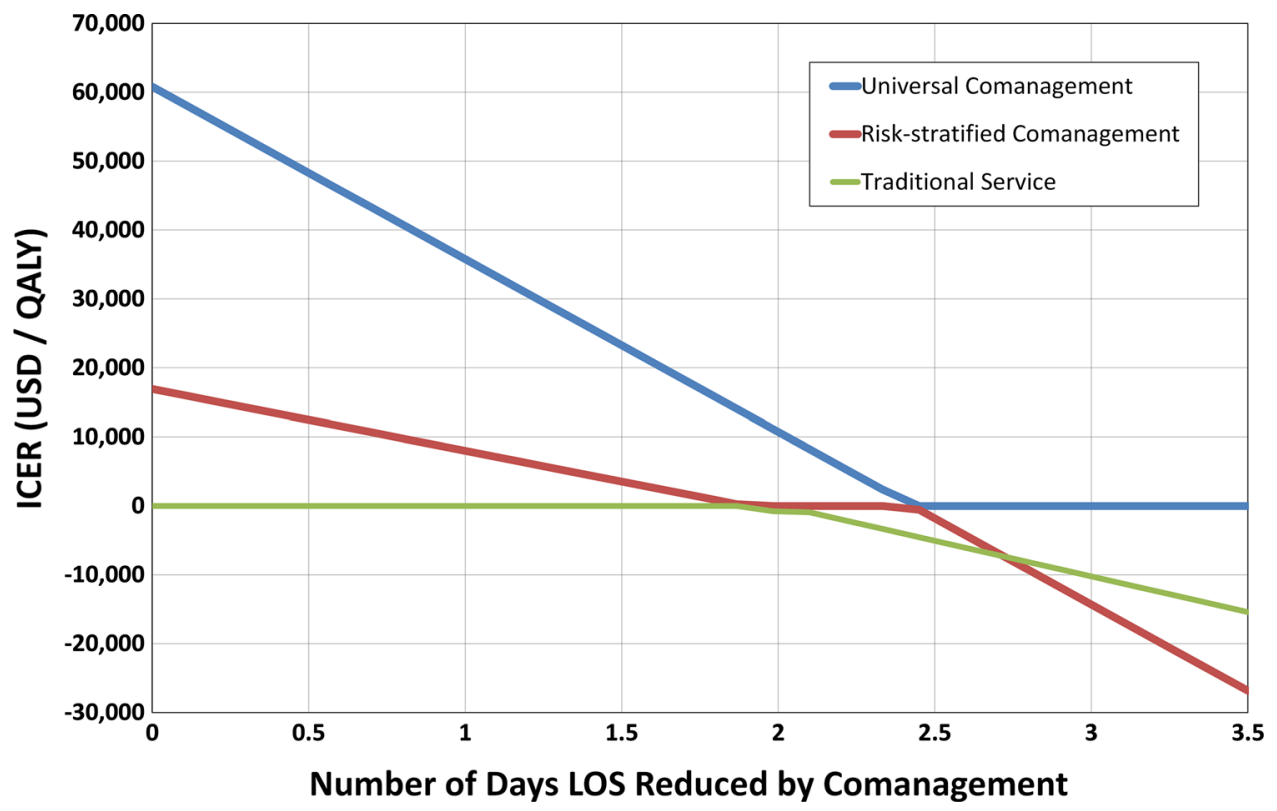

Fig. 5 The projected improvement in length of stay (LOS) for implementation of a comanagement system and its effect on incremental cost-effectiveness ratio (ICER) are shown. For an improvement in LOS greater than 1.8 days, comanagement strategies save money while improving outcomes (ie, dominant), therefore the

resources. Although there have been economic analyses evaluating the experience at a single institution, to date no analysis, to our knowledge, has combined data across multiple studies and institutions to generate conclusions and
ICER becomes negative. Even without any improvement in LOS (0 days), universal comanagement and risk-stratified comanagement show improved health outcomes and are still cost effective, with ICERs well below the cost-effectiveness threshold of USD 100,000 per QALY. QALY = quality-adjusted life-years.

guidelines that can be broadly applied to multiple hospitals of various sizes and costs structures. Our analysis shows that the effect of creating a dedicated comanagement service is encouraging: hospital length of stay decreases (likely 
secondary to broadly decreased minor complications), and mortality improves. In addition, despite substantial attention given to implant choice as an area of potential cost containment, the savings resulting from a change in management strategy can be larger than those relating to implant choices [63].

The results of our base-case and break-even analyses show that for hospitals with at least moderate volume (54 cases per year), comanagement is a cost-effective use of resources. For high-volume centers $(300+$ cases per year), it can result in cost savings. An analysis of hip fracture volume in a major metropolitan area showed that approximately $85 \%$ of patients with hip fractures are treated in centers that have at least 50 cases annually, and $23 \%$ of patients with hip fractures are cared for in centers that treat least 200 cases annually [14], so these results should be applicable in a large number of hospitals.

The decision between universal comanagement and selective triaging of only patients considered to be high risk to a more resource-intense comanagement system is less clear. Some studies considered a model of universal comanagement $[17,24,38,52,70]$, although two studies $[2,33]$ evaluating more general patient populations suggested that there may be a diminished benefit of comanagement in a younger, healthier patient population. The results of our analysis suggest that both methods are reasonable, cost effective, and generally preferable to traditional single-service management. The ideal strategy will remain a function of the risk-stratification system used, specific costs, and patient population present at each institution. To more efficiently allocate resources, future research will be needed to clarify how to more accurately triage patients and which patients benefit most from comanagement.

To improve the confidence in these results, we attempted to use extremely broad sensitivity analysis whenever there was a high degree of uncertainty regarding any given variable (eg, length of stay, salary). Despite high degrees of uncertainty with some variables, probabilistic sensitivity analysis has shown comanagement to be reliably cost effective at most hospital volumes over a large range of incremental cost-effectiveness ratios. Additionally, the model was designed conservatively, with assumptions intentionally biased against the comanagement model. For example, reductions in complications (delirium, sepsis, pneumonia) were not modeled individually as it was thought that the net decrease in length of stay shown across multiple studies likely resulted from the aggregate sum of these smaller effects and adequately captured the benefit of a comanaged service without exaggerating it. However, it is likely that these decreased complications would have other financial benefits beyond length of stay. As an example, delirium rates have been shown to be lower with direct hospitalist involvement [22, 45], and there are known additional costs associated with delirium beyond increased length of stay [42]. As our definition of quality of care and value in this patient population continues to evolve, we believe it is likely other benefits of comanagement will be identified beyond reduction in length of stay. In addition, we assumed a 10-day length of stay, although the US average is likely lower than that. Decreasing length of stay would effectively increase the service capacity of a given staff member and thus decrease their per-case costs, which would tilt the results in favor of comanagement. Finally, there may be regulatory advantages from achieving certification in hip fracture care through organizations such as the Joint Commission on Accreditation of Healthcare Organizations and the International Geriatric Fracture Society that we have not included in this analysis, which may provide further financial benefits that we did not account for in this analysis.

Our analysis also only considered the effect of a hip fracture service on the immediate perioperative period, and did not account for the future downstream benefit of increased initiation of osteoporosis treatment, which has been shown to be better in a comanagement model [22, 28] and also to be net cost effective [31, 32, 35], but this is a much more remote benefit. Additionally, although a few studies have reported improved readmission rates with comanagement [5, 39], others have reported no change [17, $24,28,52]$. We chose not to include a decreased readmission rate in our analysis, although a decreased rate would decrease the costs seen in the comanagement strategy and make it even more favorable.

The main limitation of our analysis is that the level of evidence of most of the studies evaluating implementation of a comanagement service is relatively low (usually retrospective data compared with historical controls). Ideally, future prospective randomized studies could be conducted to validate these results, although this historically has been logistically challenging to conduct. However, these results held true over a broad range of sensitivity analyses, which is encouraging.

Another important consideration is that the mortality benefit of early surgery remains controversial [4]. However, we accounted for this by conducting a broad sensitivity analysis using confidence intervals shown across several meta-analyses [48, 57, 59], which shows that these results are consistent over a reasonable range of values for mortality benefit in patients who are brought to the operating room earlier. However, this may not necessarily mean that interventions that shorten time to the operating room actually improve mortality. If that benefit were removed, then the value of a comanagement program would become strictly economic (in terms of decreased length of stay), and then comanagement would be the preferred option only in 
the scenarios described in this analysis as "cost saving" or "dominant" (vs cost effective).

Finally, determination of costs is also a challenging and important contributor to uncertainty. Hospitalist salaries were particularly difficult to estimate, as they are sparsely described in the literature. Instead, we were forced to rely on alternative (web-based) sources for salary. However, they were in a generally similar range, and consistent with US Bureau of Labor and Statistics reports, and were tested with broad sensitivity analysis to account for this uncertainty. Most of the costs used were based on US published literature, and as such these results are most directly applicable to the US market. Although we attempted to keep sensitivity analyses broad with large confidence intervals, these results may not be as directly applicable to other healthcare systems where hospital stays generally are longer and inpatient rehabilitation and nursing homes are less common (eg, Europe, Asia).

The results of our study support the formation of a formal osteoporotic fragility fracture team that includes a dedicated hospitalist, physical therapist, and social worker to comanage medically frail patients alongside orthopaedic surgeons in centers that see a moderate to high volume of patients with hip fractures. The effectiveness of universally sending all patients with osteoporotic fractures to such a service versus only patients considered to be higher risk is less clear, but our analysis suggests that with either strategy of multidisciplinary care, complication rates and length of stay improve while mortality can be reduced in a cost-effective manner. Future prospective trials should focus on validating these benefits, but this represents a promising systems change that may improve patient care while containing costs.

\section{References}

1. Arias E. United States life tables, 2002. Natl Vital Stat Rep. 2004;53:1-38.

2. Auerbach AD, Rasic MA, Sehgal N, Ide B, Stone B, Maselli J. Opportunity missed: medical consultation, resource use, and quality of care of patients undergoing major surgery. Arch Intern Med. 2007;167:2338-2344.

3. Bateman L, Vuppala S, Porada P, Carter W, Baijnath C, Burman $\mathrm{K}$, Lee R, Hargus J. Medical management in the acute hip fracture patient: a comprehensive review for the internist. Ochsner J. 2012;12:101-110.

4. Batsis JA, Phy MP, Melton LJ 3rd, Schleck CD, Larson DR, Huddleston PM, Huddleston JM. Effects of a hospitalist care model on mortality of elderly patients with hip fractures. J Hosp Med. 2007;2:219-225.

5. Boddaert J, Cohen-Bittan J, Khiami F, Le Manach Y, Raux M, Beinis JY, Verny M, Riou B. Postoperative admission to a dedicated geriatric unit decreases mortality in elderly patients with hip fracture. PLoS One. 2014;9:e83795,.

6. Borgstrom F, Strom O, Marin F, Kutahov A, Ljunggren O. Cost effectiveness of teriparatide and $\mathrm{PTH}(1-84)$ in the treatment of postmenopausal osteoporosis. J Med Econ. 2010;13:381-392.
7. Borgstrom F, Zethraeus N, Johnell O, Lidgren L, Ponzer S, Svensson O, Abdon P, Ornstein E, Lunsjo K, Thorngren KG, Sernbo I, Rehnberg C, Jonsson B. Costs and quality of life associated with osteoporosis-related fractures in Sweden. Osteoporos Int, 2006;17:637-650.

8. Braithwaite RS, Meltzer DO, King JT Jr, Leslie D, Roberts MS. What does the value of modern medicine say about the (USD) 50,000 per quality-adjusted life-year decision rule? Med Care. 2008;46:349-356.

9. Brauer CA, Coca-Perraillon M, Cutler DM, Rosen AB. Incidence and mortality of hip fractures in the United States. JAMA. 2009;302:1573-1579.

10. Burge R, Dawson-Hughes B, Solomon DH, Wong JB, King A, Tosteson A. Incidence and economic burden of osteoporosis-related fractures in the United States, 2005-2025. J Bone Miner Res. 2007;22:465-475.

11. Burgos E, Gomez-Arnau JI, Diez R, Munoz L, FernandezGuisasola J, Garcia del Valle S. Predictive value of six risk scores for outcome after surgical repair of hip fracture in elderly patients. Acta Anaesthesiol Scand. 2008;52:125-131.

12. Butler M, Forte ML, Joglekar SB, Swiontkowski MF, Kane RL. Evidence summary: systematic review of surgical treatments for geriatric hip fractures. J Bone Joint Surg Am. 2011;93:11041115.

13. Chen LT, Lee JA, Chua BS, Howe TS. Hip fractures in the elderly: the impact of comorbid illnesses on hospitalisation costs. Ann Acad Med Singapore. 2007;36:784-787.

14. Clement RC, Ahn J, Mehta S, Bernstein J. Economic viability of geriatric hip fracture centers. Orthopedics. 2013;36:e1509-1514.

15. Craig DE, Hartka L, Likosky WH, Caplan WM, Litsky P, Smithey J. Implementation of a hospitalist system in a large health maintenance organization: the Kaiser Permanente experience. Ann Intern Med. 1999;130:355-359.

16. De Rui M, Veronese N, Manzato E, Sergi G. Role of comprehensive geriatric assessment in the management of osteoporotic hip fracture in the elderly: an overview. Disabil Rehabil. 2013;35:758-765.

17. Della Rocca GJ, Moylan KC, Crist BD, Volgas DA, Stannard JP, Mehr DR. Comanagement of geriatric patients with hip fractures: a retrospective, controlled, cohort study. Geriatr Orthop Surg Rehabil. 2013;4:10-15.

18. Donegan DJ, Gay AN, Baldwin K, Morales EE, Esterhai JL Jr, Mehta S. Use of medical comorbidities to predict complications after hip fracture surgery in the elderly. J Bone Joint Surg Am. 2010;92:807-813.

19. Dy CJ, McCollister KE, Lubarsky DA, Lane JM. An economic evaluation of a systems-based strategy to expedite surgical treatment of hip fractures. J Bone Joint Surg Am. 2011;93: 13261334.

20. Egol KA, Strauss EJ. Perioperative considerations in geriatric patients with hip fracture: what is the evidence? J Orthop Trauma. 2009;23:386-394.

21. Faucett SC, Genuario JW, Tosteson AN, Koval KJ. Is prophylactic fixation a cost-effective method to prevent a future contralateral fragility hip fracture? $J$ Orthop Trauma. 2010;24:65-74.

22. Fisher AA, Davis MW, Rubenach SE, Sivakumaran S, Smith PN, Budge M. Outcomes for older patients with hip fractures: the impact of orthopedic and geriatric medicine cocare. J Orthop Trauma. 2006;20:172-178; discussion 179-180.

23. Forsen L, Sogaard AJ, Meyer HE, Edna T, Kopjar B. Survival after hip fracture: short- and long-term excess mortality according to age and gender. Osteoporos Int. 1999;10:73-78.

24. Friedman SM, Mendelson DA, Bingham KW, Kates SL. Impact of a comanaged Geriatric Fracture Center on short-term hip fracture outcomes. Arch Intern Med. 2009;169:1712-1717. 
25. Friedman SM, Mendelson DA, Kates SL, McCann RM. Geriatric co-management of proximal femur fractures: total quality management and protocol-driven care result in better outcomes for a frail patient population. J Am Geriatr Soc. 2008;56:1349-1356.

26. Giusti A, Barone A, Razzano M, Pizzonia M, Pioli G. Optimal setting and care organization in the management of older adults with hip fracture. Eur J Phys Rehabil Med. 2011;47:281-296.

27. Gold MR, Siegel JR, Russell LB, Weinstein MC, eds. Cost-effectiveness in Health and Medicine. New York, NY: Oxford University Press; 1996.

28. Gregersen M, Morch MM, Hougaard K, Damsgaard EM. Geriatric intervention in elderly patients with hip fracture in an orthopedic ward. J Inj Violence Res. 2012;4:45-51.

29. Gregory D, Baigelman W, Wilson IB. Hospital economics of the hospitalist. Health Serv Res. 2003;38:905-918; discussion 919922.

30. Haentjens P, Autier P, Barette M, Venken K, Vanderschueren D, Boonen, S; Hip Fracture Study Group. Survival and functional outcome according to hip fracture type: a one-year prospective cohort study in elderly women with an intertrochanteric or femoral neck fracture. Bone. 2007;41:958-964.

31. Hiligsmann M, Ben Sedrine W, Bruyere O, Evers SM, Rabenda V, Reginster JY. Cost-effectiveness of vitamin D and calcium supplementation in the treatment of elderly women and men with osteoporosis. Eur J Public Health. 2014;25:20-25.

32. Hiligsmann M, Evers SM, Ben Sedrine W, Kanis JA, Ramaekers B, Reginster JY, Silverman S, Wyers CE, Boonen A. A systematic review of cost-effectiveness analyses of drugs for postmenopausal osteoporosis. Pharmacoeconomics. 2015;33: 205-224.

33. Huddleston JM, Long KH, Naessens JM, Vanness D, Larson D, Trousdale R, Plevak M, Cabanela M, Ilstrup D, Wachter RM; Hospitalist-Orthopedic Team Trial Investigators. Medical and surgical comanagement after elective hip and knee arthroplasty: a randomized, controlled trial. Ann Intern Med. 2004;141:28-38.

34. Kane L, Peckham C. Medscape Physician Compensation Report 2014. Available at: http://www.medscape.com/features/slideshow/ compensation/2014/public/overview\#2. Accessed July 1, 2015.

35. Kanis JA, Hiligsmann M. The application of health technology assessment in osteoporosis. Best Pract Res Clin Endocrinol Metab. 2014;28:895-910.

36. Karagiannis A, Papakitsou E, Dretakis K, Galanos A, Megas P, Lambiris E, Lyritis GP. Mortality rates of patients with a hip fracture in a southwestern district of Greece: ten-year follow-up with reference to the type of fracture. Calcif Tissue Int. 2006;78:72-77.

37. Kates SL, Blake D, Bingham KW, Kates OS, Mendelson DA, Friedman SM. Comparison of an organized geriatric fracture program to United States government data. Geriatr Orthop Surg Rehabil. 2010;1:15-21.

38. Kates SL, Mendelson DA, Friedman SM. Co-managed care for fragility hip fractures (Rochester model). Osteoporos Int. 2010;21(suppl 4):S621-625.

39. Kates SL, Mendelson DA, Friedman SM. The value of an organized fracture program for the elderly: early results. J Orthop Trauma. 2011;25:233-237.

40. Khasraghi FA, Christmas C, Lee EJ, Mears SC, Wenz JF Sr. Effectiveness of a multidisciplinary team approach to hip fracture management. J Surg Orthop Adv. 2005;14:27-31.

41. Koval KJ, Maurer SG, Su ET, Aharonoff GB, Zuckerman JD. The effects of nutritional status on outcome after hip fracture. $J$ Orthop Trauma. 1999;13:164-169.

42. Leslie DL, Marcantonio ER, Zhang Y, Leo-Summers L, Inouye SK. One-year health care costs associated with delirium in the elderly population. Arch Intern Med. 2008;168:27-32.
43. Li J. Society of Hospital Medicine (SHM) 2007-2008 productivity and compensation survey. Available at: http://www. medscape.org/viewarticle/578134. Accessed June 10, 2015.

44. Lundberg S, Balingit P, Wali S, Cope D. Cost-effectiveness of a hospitalist service in a public teaching hospital. Acad Med. 2010;85:1312-1315.

45. Marcantonio ER, Flacker JM, Wright RJ, Resnick NM. Reducing delirium after hip fracture: a randomized trial. J Am Geriatr Soc. 2001;49:516-522.

46. Maxwell MJ, Moran CG, Moppett IK. Development and validation of a preoperative scoring system to predict 30 day mortality in patients undergoing hip fracture surgery. $\mathrm{Br} J$ Anaesth. 2008;101:511-517.

47. Medical Group Management Association (MGMA). Physician Compensation and Production Data. Available at: http://www. mgma.com/industry-data/survey-reports/physician-compensationand-production-survey. Accessed July 28, 2015.

48. Moja L, Piatti A, Pecoraro V, Ricci C, Virgili G, Salanti G, Germagnoli L, Liberati A, Banfi G. Timing matters in hip fracture surgery: patients operated within 48 hours have better outcomes: a meta-analysis and meta-regression of over 190,000 patients. PLoS One. 2012;7: e46175.

49. Nikkel LE, Fox EJ, Black KP, Davis C, Andersen L, Hollenbeak CS. Impact of comorbidities on hospitalization costs following hip fracture. J Bone Joint Surg Am. 2012;94:9-17.

50. Orosz GM, Hannan EL, Magaziner J, Koval K, Gilbert M, Aufses A, Straus E, Vespe E, Siu AL. Hip fracture in the older patient: reasons for delay in hospitalization and timing of surgical repair. J Am Geriatr Soc. 2002;50:1336-1340.

51. PayScale.com: Hospitalist Salary (United States). Available at: http://www.payscale.com/research/US/Job=Hospitalist/Salary. Accessed July 1, 2015.

52. Phy MP, Vanness DJ, Melton LJ 3rd, Long KH, Schleck CD, Larson DR, Huddleston PM, Huddleston JM. Effects of a hospitalist model on elderly patients with hip fracture. Arch Intern Med. 2005;165:796-801.

53. Radcliff TA, Henderson WG, Stoner TJ, Khuri SF, Dohm M, Hutt E. Patient risk factors, operative care, and outcomes among older community-dwelling male veterans with hip fracture. $J$ Bone Joint Surg Am. 2008;90:34-42.

54. Rushton PR, Reed MR, Pratt RK. Independent validation of the Nottingham Hip Fracture Score and identification of regional variation in patient risk within England. Bone Joint J. 2015;97:100-103.

55. Salary.com. Physician-Hospitalist Salaries. Available at: http:// www1.salary.com/Physician-Hospitalist-salary.html. Accessed July $1,2015$.

56. Schroder HM, Erlandsen M. Age and sex as determinants of mortality after hip fracture: 3,895 patients followed for 2.5-18.5 years. J Orthop Trauma. 1993;7:525-531.

57. Shiga $T$, Wajima Z, Ohe Y. Is operative delay associated with increased mortality of hip fracture patients? Systematic review, meta-analysis, and meta-regression. Can J Anaesth. 2008;55: 146-154.

58. SHM, Society of Hospital Medicine. 2014 State of Hospital Medicine Report. Available at: http://www.hospitalmedicine.org/ Web/Practice_Management/State_of_HM_Surveys/2014.aspx? hkey=a5565f9a-62a1-4a54-a6af-0483250664fa. Accessed July $1,2015$.

59. Simunovic N, Devereaux PJ, Sprague S, Guyatt GH, Schemitsch E, Debeer J, Bhandari M. Effect of early surgery after hip fracture on mortality and complications: systematic review and metaanalysis. CMAJ. 2010;182:1609-1616.

60. Singler K, Biber R, Wicklein S, Heppner HJ, Sieber CC, Bail HJ. "N-active": a new comanaged, orthogeriatric ward: observations and prospects. Z Gerontol Geriatr. 2011;44:368-374. 
61. Southern WN, Berger MA, Bellin EY, Hailpern SM, Arnsten JH. Hospitalist care and length of stay in patients requiring complex discharge planning and close clinical monitoring. Arch Intern Med. 2007;167:1869-1874.

62. Stevenson MD, Jones ML. The cost effectiveness of a randomized controlled trial to establish the relative efficacy of vitamin K1 compared with alendronate. Med Decis Making. 2011;31:43-52.

63. Swart E, Makhni EC, Macaulay W, Rosenwasser MP, Bozic KJ. Cost-effectiveness analysis of fixation options for intertrochanteric hip fractures. J Bone Joint Surg Am. 2014;96:16121620.

64. Taheri PA, Butz DA, Greenfield LJ Length of stay has minimal impact on the cost of hospital admission. J Am Coll Surg. 2000;191:123-130.

65. Thakore RV, Lee YM, Sathiyakumar V, Obremskey WT, Sethi MK. Geriatric hip fractures and inpatient services: predicting hospital charges using the ASA score. Curr Gerontol Geriatr Res. 2014;2014:923717.

66. Today's Hospitalist: 2007 Hospitalist Compensation. Available at: http://www.todayshospitalist.net/08_salary_survey/total_compensa tion/2007_hospitalist_compensation/a01_overview.html. Accessed January 2, 2015.

67. Tosteson AN, Gabriel SE, Grove MR, Moncur MM, Kneeland TS, Melton LJ 3rd. Impact of hip and vertebral fractures on quality-adjusted life years. Osteoporos Int. 2001;12:1042-1049.

68. United States Department of Labor, Bureau of Labor Statistics. May 2014 National Occupational Employment and Wage Estimates United States. Available at: http://www.bls.gov/oes/ current/oes_nat.htm. Accessed January 2, 2015.

69. United States Department of Labor, Bureau of Labor Statistics. Consumer price index. Available at: http://www.bls.gov/cpi/. Accessed January 2, 2015.

70. Vidan M, Serra JA, Moreno C, Riquelme G, Ortiz J. Efficacy of a comprehensive geriatric intervention in older patients hospitalized for hip fracture: a randomized, controlled trial. J Am Geriatr Soc. 2005;53:1476-1482.

71. Wiles MD, Moran CG, Sahota O, Moppett IK. Nottingham Hip Fracture Score as a predictor of one year mortality in patients undergoing surgical repair of fractured neck of femur. $\mathrm{Br} J$ Anaesth. 2011;106:501-504. 